$\AA_{\text {кне с позиции дерматолога и косметолога }}$

\author{
О.А. Катханова ${ }^{1}$, А.М. Катханов²
}

1 ГБОУ ВПО «Кубанский государственный медицинский университет» Минздрава России 350063, г. Краснодар, ул. Седина, д. 4

${ }^{2} 000$ «МИР-0-МЕД»

350000, г. Краснодар, ул. Рашпилевская, д. 132

Цель. Сравнить подходы врачей-дерматологов и косметологов к ведению больных акне с учетом клинической картины заболевания, возраста и пола пациентов, оценить эфффективность и безопасность наружной терапии больных акне азелаиновой кислотой.

Материал и методы. Под наблюдением в клинике «МИР-0-МЕД» находились 300 пациентов в возрасте от 14 до 48 лет с различными клиническими формами угревой болезни разной степени тяжести. Для анализа особенностей клинической картины заболевания, возрастных и половых различий больных акне, обращающихся за медицинской помощью к дерматологу и косметологу, проводили сбор статистической информации на основании первичной медицинской документации и дальнейшую ее группировку по основным и дополнительным учетным признакам. Для лечения пациентам с акне, первично обратившимся в клинику как к дерматологу, так и к косметологу, в качестве препарата первой линии рекомендовали азелаиновую кислоту в виде монотерапии и комбинации с косметологическими процедурами. Дана оценка эфффективности и безопасности наружной терапии больных акне азелаиновой кислотой.

Результаты. Клиническое выздоровление и значительное клиническое улучшение достигнуто у $94 \%$ пациентов, получавших наружную терапию азелаиновой кислотой.

Заключение. Отсутствие противоречий в слаженной работе дуэта косметолога и дерматолога предопределяет правильную последовательность и сочетание базовых лечебных мероприятий с допустимой своевременной косметологической коррекцией и является залогом успеха на пути решения проблем акне. Использование азелаиновой кислоты в лечении больных акне врачами указанных профессий существенно повышает качество и эфроективность терапевтических мероприятий.

Ключевые слова: акне, лечение, азелаиновая кислота, косметологические процедуры.

Контактная информация: okathanova@mail.ru. Вестник дерматологии и венерологии 2014; (4): 75—82. 


\title{
Acne from the point of view of dermatologists and cosmetologists
}

\author{
0.A. Katkhanova ${ }^{1}$, M.A. Katkhanov² \\ ${ }^{1}$ Kuban State Medical University \\ Sedina str, bldg 4, 350063, Krasnodar, Russia \\ ${ }^{2} 000$ "MIR-0-MED" \\ Rashpilevskaya str., 132, 350000, Krasnodar, Russia
}

\begin{abstract}
Goal. To compare approaches taken by dermatologists and cosmetologists to management of patients suffering from acne taking into consideration the clinical picture of the disease and patient's age and sex, and to assess the efficacy and safety of an external therapy with azelaic acid in acne patients.

Materials and methods. A study conducted by the MIR-0-MED Clinic involved 300 patients aged 14-48 with different forms of acne of different severity. To analyze particular features of the clinical picture of acne as well as age and sex differences in acne patients consulting dermatologists and cosmetologists, researchers collected statistics on the basis of primary medical documents, and then grouped the data by principal and additional indices. Both dermatologists and cosmetologists recommended azelaic acid in the form of a monotherapy and in a combination with cosmetic products as first-line treatment of primary acne patients. The efficacy and safety of an external therapy of acne patients with azelaic acid was assessed. Results. Clinical recovery and considerable clinical improvement was achieved in $94 \%$ of the patients who received an external therapy with azelaic acid.

Conclusion. A lack of contradictions in coordinated measures taken by cosmetologists and dermatologists predetermines the correct order and combination of basic treatment measures involving tolerable and timely cosmetic correction, which is a prerequisite for solving the acne problem. Azelaic acid used by these categories of physicians for treatment of acne patients substantially improves the quality and efficacy of therapeutic measures.
\end{abstract}

Key words: acne, treatment, azelaic acid, cosmetic manipulations. 
Акне (вульгарные угри) - широко распространенный хронический полиморфный, мультифакториальный дерматоз, который встречается в различных возрастных группах населения [1-3]. Пик заболеваемости приходится на возраст 14-18 лет, однако в последнее время наблюдается увеличение числа взрослых больных акне [4, 5]. Как активная фраза заболевания, так и исход болезни с развитием разнообразных косметически значимых вторичных изменений кожи могут сопровождаться психоэмоциональными расстройствами, преимущественно депрессивного характера, приводящими к социальной дезадаптации, снижению качества жизни пациентов. Тяжесть психоэмоциональных расстройств, как правило, не коррелирует с объективным состоянием [2-4].

Больные с акне обращаются за медицинской помощью к специалистам различного профиля, однако наиболее часто к дерматологам и косметологам. Врачи этих двух родственных специальностей занимаются оказанием медицинских услуг, связанных с патологией кожи. Ранее использовавшийся термин «дерматокосметология» наглядно демонстрировал близость этих двух дисциплин. Тем не менее если дерматовенерология как наука имеет многовековую историю, то косметология, несмотря на тысячелетнюю практику, как научное направление сформировалась совсем недавно и еще очень молода, но уже имеет свои особенности. Именно наличие этих различий препятствует синергизму подходов дерматологов и косметологов к терапии больных с акне [6-8].

Эфффективность терапии во многом предопределяется ее влиянием на патогенетические механизмы развития заболевания. Результаты новых исследований в этом направлении в значительной мере изменили классический взгляд на акне [3]. Наследственные факторы, избыток андрогенов, употребление пищи с высоким содержанием углеводов могут влиять на функцию себоцитов и стимулировать воспаление, которое приводит к усилению проницаемости стенки комедона. Гиперпродукция кожного сала, изменение его липидного состава, а также нарушение соотношения оксиданты/антиоксиданты обусловливают превалирование в эпителии процессов пролиферации над десквамацией. В развитии болезни могут участвовать и другие, менее известные функции сальных желез, а именно: их способность регулировать кожный стероидогенез, контролировать синтез андрогенов в коже, взаимодействовать с нейропептидами, синтезировать специфические липиды с антибактериальной активностью, оказывать про- и противовоспалительное действие $[9,10]$

Современные исследования свидетельствуют о предшествовании воспалительной реакции развитию гиперкератинизации фолликула [11]. Толчком к развитию воспалительной реакции является активация адаптивного (специфического) иммунитета в ответ на воздействие Propionibacterium acnes. Инициатором каскада воспалительных реакций в ответ на нарушение барьерной функции стенки фролликула может быть усиленная продукция эпидермальными кератиноцитами интерлейкина (ИЛ)-1 $\alpha$, стимулирующего увеличение экспрессии молекул адгезии ICAM-1, Е-селектин и VCAM (васкулярная адгезия клеточной молекулы 1) в перифолликулярных сосудах, что приводит к миграции моноцитов в перифолликулярные области дермы. На сегодняшний день у больных акне выявлены генетические дефекты рецепторов к ИЛ- $1 \alpha$, показана наследственная предрасположенность к комедоногенезу при мутации в гене FGFR2 [11, 12].

Недавно появились данные о ключевой роли в патогенезе акне транскрипционного фрактора FOXO1. Его дефицит усиливает трансактивацию андрогенных рецепторов и модулирует активность ядерных фракторов и ключевых генов, вовлеченных в пролиферацию кератиноцитов сально-волосяного фолликула, липогенез себоцитов и экспрессию перифолликулярных воспалительных цитокинов.

Многообразие фракторов, участвующих в сложных процессах фрормирования акне, диктует необходимость проведения комплексной терапевтической коррекции. Препаратом, удовлетворяющим потребности дерматологов (а значит, действующего на основные патогенетические механизмы болезни) и косметологов (прежде всего хорошая сочетаемость с косметологическими процедурами), является азелаиновая кислота (в РФ оригинальный препарат зарегистрирован под торговым названием Скинорен), что позволяет ее рекомендовать в качестве базовой терапии акне [13].

Скинорен относится к высокотехнологичным лекарственным препаратам. Входящая в его состав азелаиновая кислота имеет микронизированную форму, что является несомненным преимуществом по сравнению с аналогами.

Противовоспалительное действие азелаиновой кислоты основано на ее влиянии на образование свободных радикалов, синтез цитокинов, блокировку важных провоспалительных путей, опосредованных митогенактивированной протеинкиназой (MAPK) и ядерным фактором каппа-B (NF-кB); активацию противовоспалительных белков PPAR $\gamma$ (активируемый пролифераторами пероксисом рецептор $\gamma$ ) и подавление эфффектов биологически активных веществ, например калликреина-5.

Противомикробное действие азелаиновой кислоты, ее бактериостатическое и бактерицидное действия в отношении $P$. acnes и Staphylococcus epidermidis peaлизуются за счет разобщения трансмембранного градиента $\mathrm{pH}$, способности подавления транспорта необходимых нутриентов внутрь бактерии $[13,14]$.

Антикератинизирующее действие Скинорена связано с восстановлением нарушенной диффреренцировки кератиноцитов в устье фолликулов. Кератоли- 
тический эффрект способствует регрессу фролликулярного гиперкератоза, а также может быть использован в качестве предпилинговой подготовки для выравнивания толщины рогового слоя.

Важным аспектом терапии акне является купирование посттравматической пигментации и поствоспалительного меланоза, которые, как правило, развиваются вторично по отношению к акне и часто связаны с чрезмерно агрессивным лечением. Азелаиновая кислота подавляет активность тирозиназы посредством конкурентного ингибирования. Селективное цитотоксическое и антипролиферативное действие в отношении аномальных меланоцитов позволяет добиться отбеливающего эффректа и играет ведущую роль в программах по стабилизации и ингибированию меланогенеза.

Антиоксидантные эффректы азелаиновой кислоты опосредуются за счет снижения выработки активных форм кислорода нейтрофильными гранулоцитами. Это является несомненным плюсом в лечении постпубертатного акне, на фоне первых признаков старения и уменьшения с возрастом активности репаративных процессов. Азелаиновая кислота не обладает тератогенным, мутагенным и эмбриотоксическим свойствами и разрешена к применению для лечения акне у беременных и кормящих, не имеет ограничений по возрасту, что является дополнительным преимуществом при назначении женщинам 18-35 лет [15, 16].

Поскольку лечение акне требует длительных, неоднократных курсов, очень важным критерием выбора препарата служит профиль его безопасности и отсутствие развития резистентности, что отражается на эффективности терапии.

После нанесения на кожу препарата Скинорен азелаиновая кислота проникает во все слои эпидермиса и собственно кожи, создавая высокие эффективные концентрации в месте своего действия. Это определяет возможность максимальной эфрфективности Скинорена вне зависимости от стадии, локализации, распространенности заболевания. В отличие от антибиотиков азелаиновая кислота не индуцирует развитие устойчивости и эффективна против уже антибиотикоустойчивых штаммов. В отличие от других средств, используемых для лечения акне, азелаиновая кислота (Скинорен гель, крем) не обладает фотосенсибилизирующими свойствами и не участвует в развитии фототоксических реакций [13]. Именно поэтому ее препараты могут применяться вне зависимости от активности инсоляции, в том числе в летний период, и сочетаться с косметологическими процедурами (технология IPL — Intense Pulsed Light, фрракционный фрототермолиз и др.).

Цель работы: сравнить подходы врачей-дерматологов и косметологов к ведению больных акне с учетом клинической картины заболевания, возраста и пола пациентов, оценить эфрфективность наружной терапии больных акне азелаиновой кислотой.

\section{Материал и методы}

Под наблюдением в клинике «МИР-О-МЕД» находились 300 пациентов в возрасте от 14 до 46 лет с различными клиническими формами акне разной степени тяжести.

Для анализа особенностей клинической картины заболевания, возрастных и половых различий больных акне, обращающихся за медицинской помощью к дерматологу и косметологу, проводили сбор статистической информации на основании первичной медицинской документации и дальнейшую ее группировку по основным и дополнительным учетным признакам. Для проведения анализа выделили 5 возрастных групп: 12-18, 19-25, 26-32, 33-39, 40-46 лет.

Средний возраст пациентов составил $23 \pm 3$ года. Длительность заболевания варьировала от 2 мес. до 17 лет. Персистирующие фрормы акне отмечались у $42 \%$, «поздние акне» - у 14\% больных. Комплексное обследование пациентов включало: заполнение индивидуальной карты, осмотр, сбор анамнеза, оценку клинической картины, общеклинические тесты, консультации гастроэнтеролога, гинеколога, эндокринолога. Степень тяжести акне (СТА) оценивалась согласно классификации Американской академии дерматологии [2, 6]:

1-я СТА - комедоны и до 10 папул;

2-я СТА - комедоны, папулы, до 10 пустул;

3-я СТА - комедоны, папулы, пустулы, до 5 узлов;

4-я СТА - выраженная воспалительная реакция с формированием множественных узлов и кист.

Все пациенты получали комплексную терапию, адекватную их состоянию, степени тяжести заболевания, с учетом сопутствующей патологии. В качестве препарата первой линии первично обратившимся пациентам в клинику как к дерматологу, так и к косметологу рекомендовали азелаиновую кислоту (Скинорен). Скинорен применяли в зависимости от степени тяжести акне в виде монотерапии, в комбинации с другими лекарственными препаратами, косметологическими процедурами и аппаратными методами воздействия, а также в качестве поддерживающей терапии (рис. 1).

Препарат в виде 15\% геля наносили 2 раза в сутки на проблемные участки кожи. По мере купирования островоспалительных явлений с целью усиления патогенетического действия и профилактики вторичной гиперпигментации предпочтение отдавали азелаиновой кислоте в большей концентрации (20\%) в форме крема, текстура которого способствует проникновению действующего вещества в более глубокие слои кожи. Продолжительность терапии составила в среднем 4 мес. Клиническая оценка эффективности лечения проводилась по следующим критериям: клиническое выздоровление - регресс элементов сыпи 


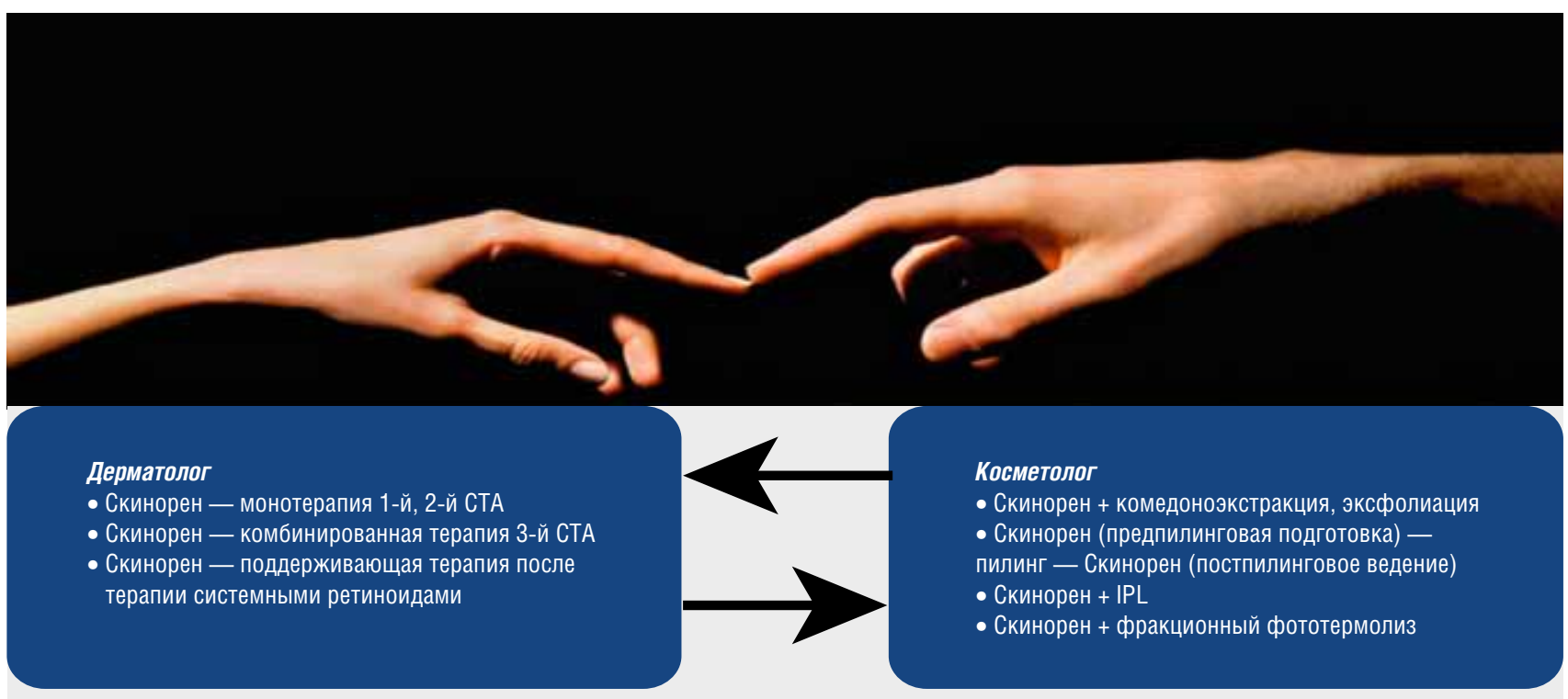

Рис. 1. Схемы терапии акне с использованием Скинорена

на 75-100\%; значительное улучшение - регресс элементов сыпи на 50-75\%; улучшение - регресс элементов сыпи на 25-50\%; отсутствие эффректа - регресс элементов сыпи менее $25 \%$.

Полученные результаты обработаны статистическими методами с использованием пакета прикладных программ Statistika 6, Microsoft Excel 2010.

\section{Результаты и обсуждение}

Ретроспективный анализ обращений за медицинской помощью больных с акне к врачам-дерматологам и косметологам показал, что 183 (61\%) пациента отдали предпочтение дерматологу. При этом только 129 (43\%) больных впервые пришли на прием в клинику, 171 (57\%) пациент имел предшествующий опыт лечения: у дерматолога - 57 (19\%) больных, у косметолога - 69 (23\%) и 45 (15\%) соответственно у врачей смежных специальностей различных лечебных учреждений.

Распределение пациентов по гендерному признаку на приеме у дерматолога и косметолога продемонстрировало, что мужчины чаще обращаются за помощью к дерматологу (48\%), чем к косметологу (14\%), тогда как в женской популяции наблюдалось обратное соотношение (52 и 86\% соответственно).

Анализ числа обращений пациентов с акне к указанным специалистам в пяти возрастных группах на первый взгляд показал их случайный, разнонаправленный характер и отсутствие связи между ними (рис. 2). Так, в возрастной группе 12-18 лет число обращений к дерматологу трехкратно превосходит аналогичный показатель у косметолога. Однако отме- ченное преобладание числа обращений больных акне к дерматологу полностью нивелировалось в возрастной группе 19-25 лет, тогда как в возрастной группе 26-32 года преобладает число посещений косметолога. Отмеченная тенденция, несмотря на снижение числовых значений параметров, четко сохранялась в возрастных группах 33-39 и 40-46 лет.

Основные жалобы пациентов сводились к появлению высыпаний на коже и повышенной ее жирности. При изучении наследственности у $38 \%$ больных отмечались признаки акне у родителей и у $10 \%-$ у близких родственников. Наличие «андрогенных дерматопатий» (симптомов избытка уровня/активности андрогенов: алопеция, акне, себорея, гирсутизм) по одной ветви родства отмечалось в $75 \%$ случаев, у обоих родителей - в 25\%. При анализе триггерных факторов и сопутствующей патологии чаще всего обострения пациенты связывали с погрешностями в питании - 24\%, стрессом - 18, инсоляцией -12 , косметическими средствами - 9\%. Патология желудочно-кишечного тракта была выявлена у $37 \%$ пациентов, эндокринные дисфункции - у 40\%, изменения гормонального фрона - у $32 \%$, воспалительные заболевания органов малого таза - у 19\%, нарушения менструальной функции - у $28 \%$. Анамнестический опрос показал, что ухудшение течения акне в предменструальный период отмечали 44,3\% пациенток. Это было более выражено в возрастной группе старше 25 лет. Четкой связи обострений с временем года проследить не удалось.

В ходе исследования проводили клинический осмотр и оценку степени тяжести акне (рис. 3). Пре- 

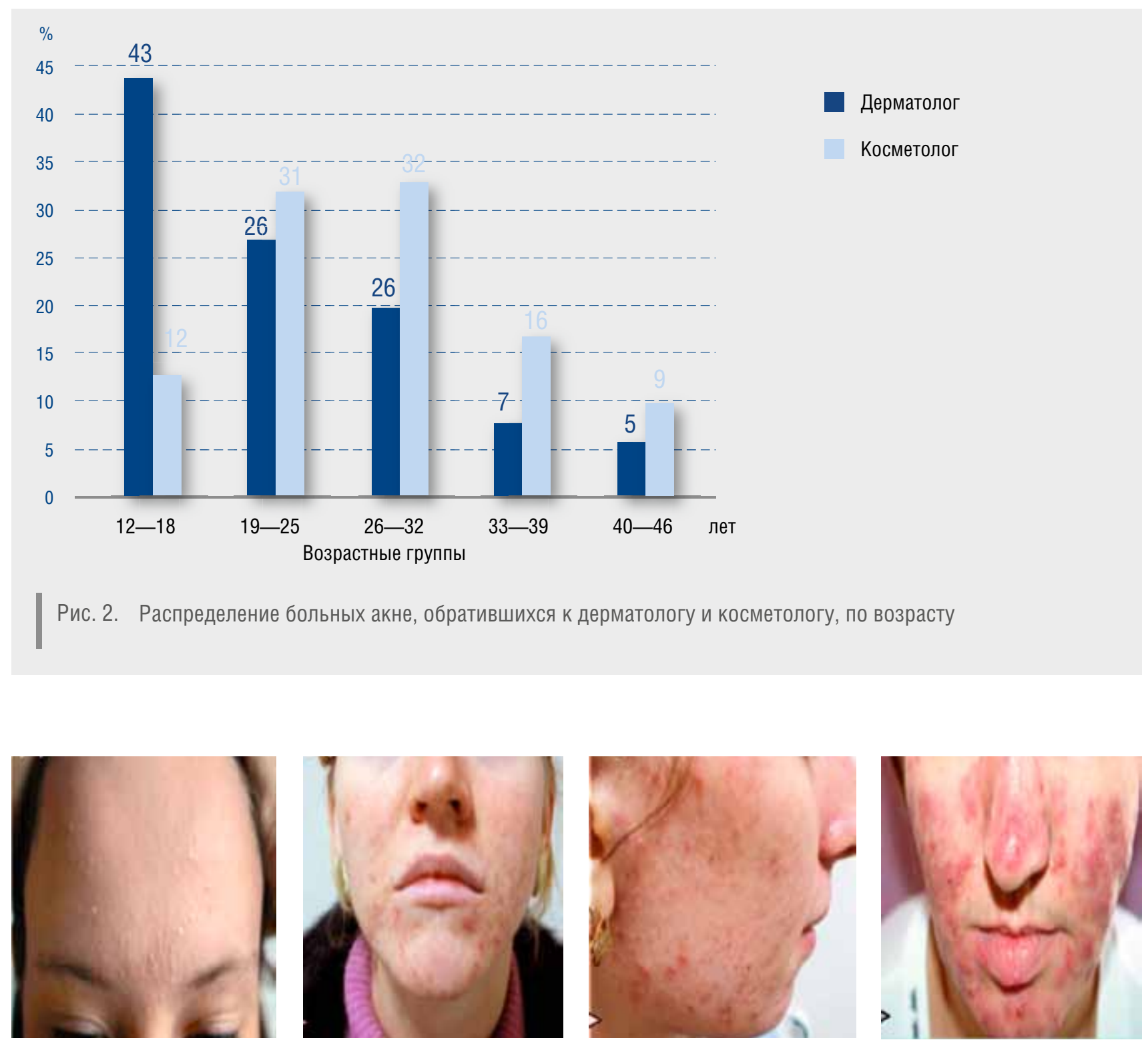

Рис. 3. Обследованные пациенты с различной степенью тяжести акне

имущественной локализацией проявлений болезни в 98\% случаев была кожа лица. В возрастной группе 12-18 лет превалировало центрофрациальное (Т-зона) расположение элементов с преимущественной локализацией в верхней трети лица, отличающееся выраженным полиморфизмом, включающим широкий спектр проявлений от комедонов, как открытых, так и закрытых, до множественных гнойничков, узловато-кистозных образований. У взрослых женщин очаги обычно располагались в нижней трети лица - на щеках, подбородке и периорально в виде единичных папуло-пустулезных элементов, сопровождающихся выраженной воспалительной реакцией.

У большинства обследованных пациентов преобладала папуло-пустулезная форма дерматоза, соответствующая в зависимости от количества элементов 2-й или 3-й степени тяжести.

Распределение пациентов в зависимости от степени тяжести акне на приеме у дерматолога и косметолога наглядно демонстрирует, что пациентов с тя- 


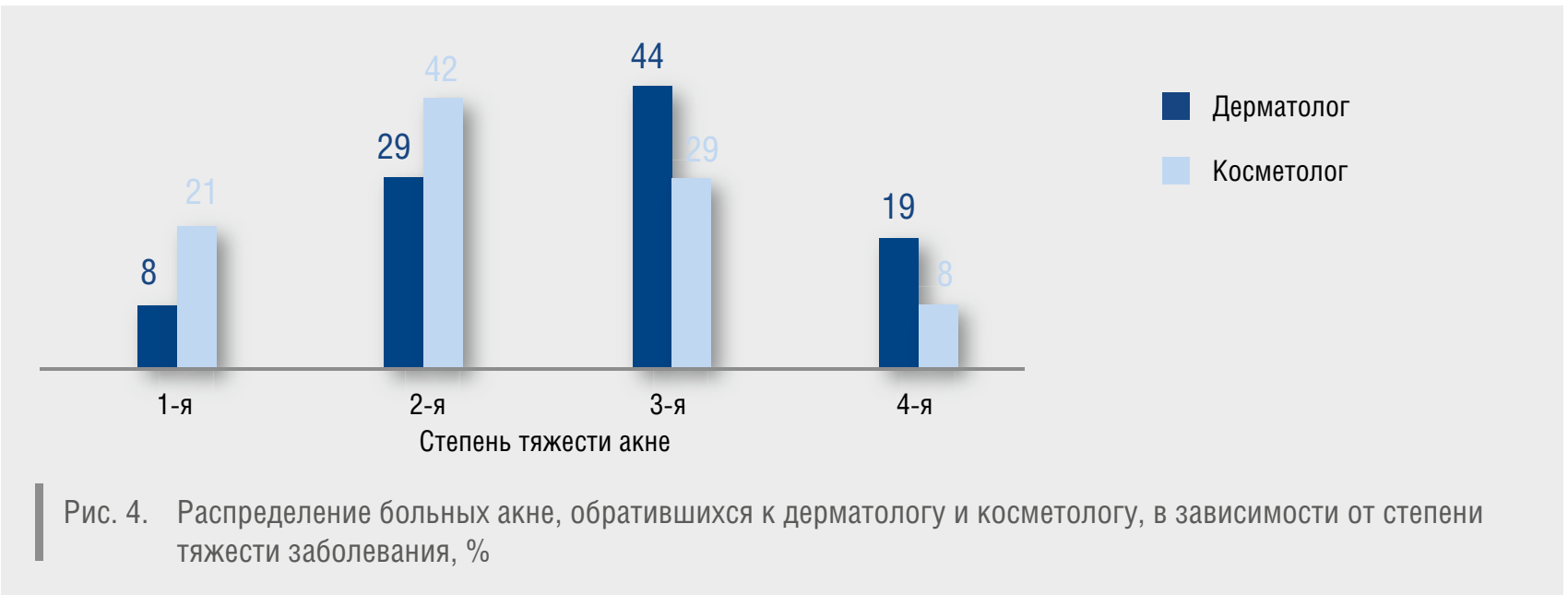

желым течением патологического процесса у дерматолога было больше, процент тяжелых фрорм (3, 4-я степень) в 2 раза выше, чем у косметологов (рис. 4).

При оценке эфффективности лечения пациентов с акне с использованием в качестве базисного средства наружной терапии препарата Скинорен по описанным выше критериям было выявлено, что клиническое выздоровление и значительное клиническое улучшение (регресс элементов сыпи на 50-100\%) были достигнуты у 94\% респондентов (рис. 5).

Комплексная оценка качества проведенной терапии предусматривает учет индивидуальных особенностей пациента (психосоциальный статус), генетическую предрасположенность, детородный статус, выраженность, тяжесть и продолжительность заболевания, ответ на предыдущую терапию, предрасположенность к рубцеванию и поствоспалительной пигментации, потенциал к побочным действиям, предпочтения самих пациентов и финансовую составляющую $[2,3,6,17]$.

Недостаточная информированность дерматологов о методах косметологической коррекции, а косметологов - о патогенетически обоснованных средствах терапии, незрелость специалистов (отсутствие клинического опыта), коммерческая заинтересованность, ангажированность профессиональных средств и другие экономические нюансы приводят к неудачам терапии как одних, так и других специалистов.

В последнее время в научной литературе появляется все больше работ, посвященных использованию лекарственных средств в сочетании с косметологическими процедурами, при этом практически все косметологические процедуры в той или иной степени сопровождаются повреждением кожного покрова и, как следствие, развитием воспалительной реакции. B. Dreno и соавт. были впервые даны рекомендации по терапии акне у взрослых женщин, в которых отдельным разделом изложены рекомендации по вспо- могательной терапии и косметической коррекции [4]. Я.А. Юцковская отмечает высокую эффрективность наружного лечения акне азелаиновой кислотой в сочетании с процедурой контролируемой микродермабразии [6]. А.В. Сайбель представлены материалы, подтверждающие целесообразность и обоснованность комбинации Скинорена с химическими пилингами [7]. Таким образом, способность азелаиновой кислоты влиять на основные звенья патогенеза акне, с одной стороны, синергизм воздействия и возможность сочетания с методами эстетической коррекции, с другой,

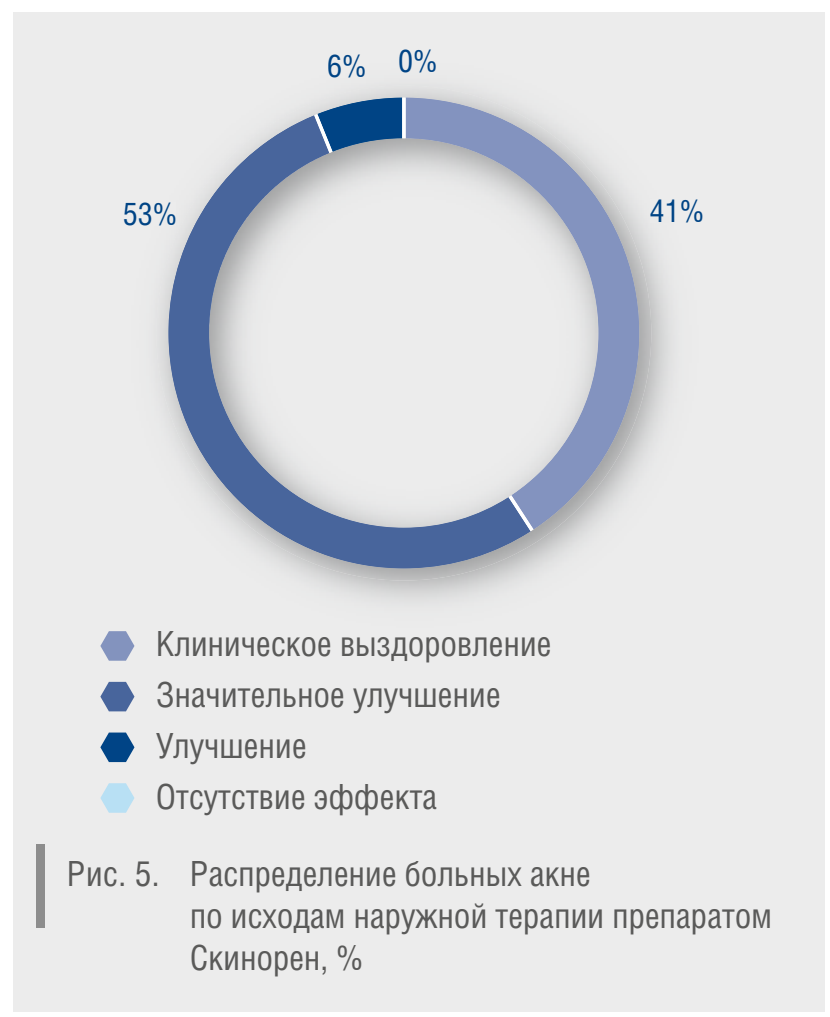


комфортность и удобство применения, с третьей, позволяют рекомендовать препарат Скинорен для комплексного лечения акне.

Пытаясь оценить результаты лечения акне, определить наиболее успешных специалистов дерматологов или косметологов, мы пришли к выводу, что такая постановка вопроса является некорректной, так как врачи этих профессий нацелены на позитивный результат, а группы пациентов, обращающихся к ним, трудносопоставимы по возрастным, гендерным признакам и тяжести клинических проявлений. Тем не менее следует отметить, что имеются различия в приоритетах. Дерматологи видят свою основную цель при лечении больных акне в преодолении воспалительных явлений, купировании новых высыпаний и мало ориентированы на остающиеся вторичные изменения ко- жи и внешний вид больного. Косметологи, имеющие сравнительно немного четких рекомендаций по ведению пациентов с акне, во многом действуют эмпирически, ставя во главу угла эстетическую составляющую терапии.

\section{Заключение}

Отсутствие противоречий, слаженность действий дуэта косметолога и дерматолога определяют правильную последовательность и сочетание базовых лечебных мероприятий с допустимой своевременной косметической коррекцией и являются залогом успеха на пути решения проблем акне.

Использование Скинорена врачами указанных профессий существенно повышает качество и эффрективность терапевтических мероприятий. I

\section{Литература}

1. Nast A., Dreno B., Betolli V. et al. European evidence-based S3 quidelines for the treatment of acne J Eur Acad Dermatol Venereol 2012; 26 (Suppl.): $1-29$.

2. Potekaev N.N., Goriachkina M.V. Certain aspects of diagnostics and treatment of refractory acne in the women. Clin Dermatol and Venerol 2012; 1: 72-78. [Потекаев Н.Н., Горячкина М.В. Некоторые аспекты диагностики и лечения рефрактерных акне у женщин. Клин дерматол и венерол 2012; 1: 72-77.]

3. Volkova Ye.N., Grigoriyeva A.A., Yelistratova I.V Pathogenic therapy of acne patients Vestn Dermatol i Venerol 2012; 6: 82-89. [Волкова Е.H. Григорьева А.А., Елистратова И.В. Патогенетическая терапия больных акне. Вест дерматол и венерол 2012; 6: 82-89.]

4. Dreno B., Layton A., Zouboulis C.C. et al Adult female acne: a new paradigm J Eur Acad Dermatol Venereol 2013; 27: 1063-1070.

5. Choi C., Lee D., Kim H. The clinical features of late onset acne compared with early onset acne in women. J Eur Acad Dermatol Venereol 2011; 25: 454-461.

6. Yutskovskaya Ya.A., Taran M.G., Dvoryaninova I.E. Printsipy naruzhnogo lecheniya akne v sochetanii s apparatnymi metodami vozdeystviya. Eksper i klin dermatokosmetol 2012; 3: 20-23. ГЮцковская Я.А., Таран М.Г., Дворянинова И.Е. Принципы наружного лечения акне в сочетании с аппаратными методами воздействия. Экспер и клин дерматокосметол 2012; 3: 20—23.]
7. Saybel' A.V. Skinoren i pilingi v lechenii akne Kosmetic International 2012; 2: 34-36. [Сайбель А.В. Скинорен и пилинги в лечении акне Kosmetic International 2012: 2: 34 - 36.]

8. Butov Yu.S., Akhtyamov S.N., Demina O.M. i soavt. Fotodinamicheskaya terapiya ugrevoy bolezni. Rus J Skin and Sex Transmit Diseases 2007; 3: 64-67. [Бутов Ю.С., Ахтямов С.Н., Демина 0.М. и соавт. Фотодинамическая терапия угревой болезни. Рос журн кож и вен бол 2007; 3: 64-67.]

9. Zouboulis C.C., Eady A., Philpott M. et al. What is the pathogenesis of acne? Exp Dermatol 2005; 14: 143-152.

10. Lipova E.V., Shkoda S.A., Glazko I.I. i soavt. Innovatsionnye tekhnologii v naruzhnoy terapii akne. Modern Probl Dermatovenerol, Immunol and Medi Cosmetol 2011; 2: 54—60. [Липова Е.В. Шкода С.А. Глазко И.И. и соавт. Инновационные технологии в наружной терапии акне. Соврем пробл дерматовенерол, иммунол и врач косметол 2011; 2: 54-60.]

11. Holland D.B., Jeremy A.H. The role of inflammation in the pathogenesis of acne and acne scarring. Semin Cutan Med Surg 2005; 24: 79_83.

12. Fritsch M., Orfanos C.E., Zouboulis C.C. Sebocytes are the key regulators of androgen homeostasis in human skin. J Invest Dermatol 2001; 116:793-800.
13. Dukhanin A.S. The current criteria for rational pharmacotherapy of acne in women. The viewpoint of a clinical pharmacologist. Clin Dermatol and Venerol 2012; 2: 108-117. [Духанин А.C. Современные критерии рациональной фармакотерапии акне у женщин. Взгляд клинического фармаколога. Клин дерматол и венерол 2012; 2: 108-117.]

14. Thiboutot D. Versatility of azelaic acid $15 \%$ gel in treatment of inflammatory acne vulgaris. J Drugs Dermatol 2008; 7: 13-16.

15. Webster G. Combination azelaic acid therapy for acne vulgaris. J Am Acad Dermatol 2000; 43: S47-50.

16. Gollnick H.P., Graupe K., Zaumseil R.P. Azelaic acid $15 \%$ gel in the treatment of acne vulgaris. Combined results of two doubleblind clinical comparative studies. J Dtsch Dermatol Ges 2004: 2: 841-847.

17. Tlish M.M., Katkhanova O.A., Kuznetsova T.G., Naatyzh Zh.Yu. Innovations in the external therapy of acne. Vestn Dermatol i Venerol 2013; 2: 79-83. [Тлиш М.М., Катханова О.А., Кузнецова Т.Г., Наатыж Ж.Ю. Инновации наружной терапии акне. Вестн дерматол и венерол 2013; 2: 79-83.]

об авторах:

О.А. Катханова - д.м.н., профессор кафредры дерматовенерологии ГБОУ ВПО КубГМУ Минздрава России, Краснодар

А.М. Катханов - д.м.Н., профессор, главный врач клиники «МИР-0-МЕД», Краснодар 